\title{
Bentuk-bentuk Pemulihan Akhlak bagi Pesalah Seks di Malaysia: Suatu Sorotan Literatur
}

\author{
Classifications of Moral Rehabilitation for Sex \\ Offenders in Malaysia: A Literature Review
}

\begin{abstract}
Nursyahidah Ibrahim
Department of Da'wah and Human Development, Academy of Islamic Studies, University of Malaya, 50603 Kuala Lumpur, Malaysia. syahidah771@um.edu.my

Nurul Husna Mansor

Department of Da'wah and Human Development, Academy of Islamic Studies, University of Malaya, 50603 Kuala Lumpur, Malaysia.nurulhusna@um.edu.my

Yusmini Md Yusoff

Department of Da 'wah and Human Development, Academy of Islamic Studies, University of Malaya, 50603 Kuala Lumpur, Malaysia. yusmini@um.edu.my
\end{abstract}

DOI: https://doi.org/10.22452/usuluddin.vol48no2.1

\begin{abstract}
Sexual misconduct is not a new occurrence in Malaysia. It is a global issue that has raised concern and threatened the well-being of a society. From here, a recovery intervention program was introduced to help those who are involved with anti-social behaviour in order to restore their physical and spiritual welfares. The existence of rehabilitation institutions and correctional centres in Malaysia plays a significant role as it acts as platforms in implementing moral rehabilitation programs by formulating various modules and activities. In summary, there are two forms of moral rehabilitation which are institutional rehabilitation and communal rehabilitation. Hence, this paper will identify the types of moral rehabilitation meant for sex offenders at rehabilitation institutions and correctional centres in Malaysia. This paper applies the qualitative approach through descriptive analysis method based on findings from previous studies. Based on theses findings, it is found that there are generally four types of moral rehabilitation in rehabilitation institutions and correctional centres which are religious/spiritual rehabilitation, rehabilitation based on Islamic guidance and counselling, rehabilitation based on vocational training and education and rehabilitation based on social and physical development.
\end{abstract}

Keywords: sexual misconducts, type of moral rehabilitation, social rehabilitation, institutional rehabilitation, sex offenders, correctional centres.

\section{Abstrak}

Salah laku seksual bukan suatu perkara asing di Malaysia. Ia merupakan isu global yang mengundang kebimbangan dan menggugat kesejahteraan 
hidup masyarakat. Bertitik tolak daripada itu, program intervensi berbentuk pemulihan telah diwujudkan bagi membantu mereka yang terjebak dengan tingkah laku anti sosial ini bagi memulihkan fizikal dan spiritual mereka. Kewujudan institusi pemulihan dan pusat koreksional di Malaysia kini merupakan platform yang berperanan penting dalam melaksanakan program pemulihan akhlak dengan merangka pelbagai pengisian dan pendekatan. Secara ringkasnya, terdapat dua bentuk pemulihan akhlak iaitu pemulihan di institusi dan pemulihan dalam komuniti. Justeru, makalah ini akan meninjau bentuk-bentuk pemulihan akhlak di institusi pemulihan dan pusat koreksional bagi pesalah seks di Malaysia. Kajian ini berbentuk kualitatif dengan menggunakan metode analisis deskriptif daripada hasil dapatan kajian-kajian yang lepas. Hasil tinjauan terhadap kajian-kajian lepas mendapati secara umumnya, bentuk pemulihan akhlak di rata-rata institusi pemulihan dan pusat koreksional dapat dibahagikan kepada empat bentuk iaitu pemulihan berasaskan keagamaan/kerohanian, pemulihan berasaskan bimbingan dan kaunseling Islam, pemulihan berasaskan pengintegrasian latihan vokasional dan pendidikan serta pemulihan berasaskan pembangunan fizikal dan sosial.

Kata kunci: salah laku seksual, bentuk-bentuk pemulihan akhlak, pemulihan sosial, pemulihan di institusi, pesalah seks, pusat koreksional

\section{Pendahuluan}

Dunia hari ini termasuk Malaysia sedang bergelut dengan masalah seks global yang dianggap kritikal. Gejala salah laku seksual seperti seks bebas, seks rambang, homoseksual, biseksual, sumbang mahram, pelacuran, pedofilia, khalwat, rogol dan seumpamanya tidak lagi menjadi perkara asing dalam masyarakat. Hal tersebut seolah-olah menjadi suatu budaya yang tidak lagi dianggap sebagai suatu perbuatan yang salah dan berdosa. Berikutan itu, penubuhan institusi pemulihan dan pusat koreksional merupakan antara inisiatif yang baik oleh pihak bertanggungjawab seperti kerajaan, Non Goverment Organisation (NGO) dan masyarakat dalam usaha membantu memulihkan golongan remaja bermasalah terutamanya remaja yang terlibat dengan kes-kes juvana dan kes salah laku seksual.

Berdasarkan Akta Kanak-kanak 2001, institusi pemulihan diklasifikasikan sebagai salah satu tempat bernaung yang ditubuhkan bagi tujuan pemeliharaan, perlindungan dan pemulihan kanak-kanak atau remaja bermasalah sosial termasuk masalah 
seksual. ${ }^{1}$ Di Malaysia, sejarah penubuhan pusat perlindungan wanita oleh pihak kerajaan adalah sejak 57 tahun yang lalu, manakala bagi pusat perlindungan wanita bukan kerajaan (NGO) pula dikenal pasti wujud kira-kira 27 tahun yang lalu. ${ }^{2}$ Menurut sumber lain pula, pusat perlindungan wanita telah ditubuhkan sejak tahun 1975 lagi. Namun penubuhannya tidak diwar-warkan kerana menghormati sensitiviti budaya dan agama masyarakat setempat di negara ini. ${ }^{3}$ Selain itu, pihak kerajaan telah memperuntukkan sejumlah dana untuk menubuhkan pusat perlindungan wanita di bawah kelolaan Jabatan Kebajikan Masyarakat Malaysia (JKMM) dengan mendapat bantuan daripada 14 pertubuhan bukan kerajaan (NGO) yang mempunyai pengalaman dan kepakaran dalam mengendalikan remaja bermasalah dengan aktivitinya dipantau oleh kerajaan. ${ }^{4}$

Rata-rata institusi pemulihan dan pusat koreksional yang ditubuhkan dikendalikan oleh beberapa pihak seperti kerajaan, bukan kerajaan (NGO) dan persendirian, antaranya ialah Raudhatus Sakinah (JIM), Baitul Islah Perkid, Rumah Perlindungan dan Pemulihan Wanita Darul Wardah (ABIM), Pusat Perlindungan Wanita Baitul Ehsan (MAIS), Taman Seri Puteri (JKMM), Asrama Akhlak (JKMM), Rumah Puteri Arafiah (PERKAWANIS), Rumah Perlindungan Baitus Solehah, Rumah Perlindungan Baitul Fiqh, Dar Assaadah (MAIWP), Sekolah Harapan Rumah Harapan (MAIM), Jabatan Penjara Malaysia (JPM) dan lain-lain lagi. Menerusi penubuhan institusi pemulihan dan pusat koreksional, modul pemulihan yang mengandungi pengisian dan pendekatan yang pelbagai telah dijalankan. Modul tersebut merupakan bimbingan dan panduan bagi memulihkan fizikal dan spiritual mereka yang telah terjebak dengan tingkah laku anti sosial. Walau bagaimanapun, penubuhan kesemua institusi pemulihan dan pusat

Akta Kanak-Kanak 2001 (Akta 611).

2 Nor Jana Saim et al., "Listen to the Voices of Unwed Teenage Mothers in Malaysian Shelter Homes: An Explorative Study," Global Journal of Health Science 5, no. 5 (2013), 20-30.

3 Mohd Al Qayum Azizi, "Rumah Perlindungan Kanak-kanak, Wanita Wujud Sejak 1975," laman sesawang Mstar, dicapai 5 Januari 2020, https://www.mstar .com.my/lokal/semasa/2010/10/07/rumah-perlindungan-kanakkanak-wanitawujud-sejak-1975.

4 Mohd Al Qayum Azizi, "Rumah Perlindungan Kanak-kanak, Wanita Wujud Sejak 1975." 
koreksional tersebut adalah menuju kepada satu matlamat yang sama iaitu untuk membantu memulihkan akhlak penghuni di samping memenuhi keperluan fizikal dan spiritual mereka.

Secara umumnya, program pemulihan merupakan satu bentuk perkhidmatan sosial yang baik bertujuan memulihkan individu yang menghadapi masalah tingkah laku negatif. ${ }^{5}$ Lazimnya, program pemulihan tersebut tertumpu kepada usaha-usaha pembentukan semula akhlak dan tingkah laku pesalah melalui pengisian dan modul pemulihan yang telah dirangka. Di Malaysia, program pemulihan akhlak dijalankan melalui dua platform iaitu sama ada di institusi atau dalam komuniti. ${ }^{6}$ Namun, makalah ini hanya memfokuskan perbincangan mengenai program pemulihan akhlak di institusi sahaja. Hal yang demikian kerana peranan institusi pemulihan dikatakan cukup signifikan dalam membantu proses pemulihan akhlak pesalah sepertimana yang termaktub di dalam Akta Kanak-Kanak 2001. ${ }^{7}$ Dalam konteks pemulihan di institusi, institusi pemulihan dan pusat koreksional merupakan antara institusi yang diwujudkan secara khusus oleh kerajaan mahupun NGO bagi menjalankan fungsi masing-masing, bukan sekadar untuk memenuhi keperluan fizikal penghuni bahkan juga spiritual.

Peranan masyarakat dikatakan signifikan dalam membantu proses pemulihan akhlak dan sosial pesalah terutamanya yang melibatkan golongan remaja. ${ }^{8}$ Sebagaimana firman Allah SWT:
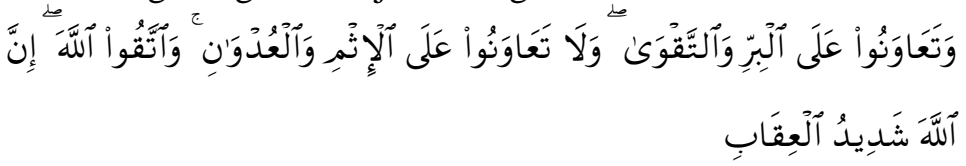

Al-Mā'idah 5:2

Terjemahan: Dan hendaklah kamu bertolong-tolongan untuk membuat kebajikan dan bertakwa, dan janganlah kamu bertolong-tolongan pada melakukan dosa (maksiat) dan

5 Richard Barton, "Psychosocial Rehabilitation Services in Community Support Systems: A Review of Outcomes and Policy Recommendations," Psychiatric Services 50, no. 40 (1999), 525-534.

6 Nurul Husna Mansor, "Modul Keagamaan untuk Remaja Hamil Luar Nikah di Pusat Perlindungan Wanita di Selangor: Kajian Pelaksanaan dan Masalah" (Tesis Kedoktoran, Universiti Malaya, Kuala Lumpur, 2016), 225-250.

7 Akta Kanak-kanak 2001 (Akta 611).

8 Muhamad Razak Idris, beliau adalah Pensyarah Kanan di Fakulti Pengajian Islam, Universiti Kebangsaan Malaysia. 
pencerobohan. Dan bertakwalah kepada Allah kerana sesungguhnya Allah Maha Berat azab seksa-Nya bagi sesiapa yang melanggar perintah-Nya.

Melalui program pemulihan di institusi, pesalah seks akan ditempatkan sama ada di institusi pemulihan atau pusat koreksional tertentu. Pergerakan mereka akan sentiasa terkawal dan tidak terdedah kepada persekitaran luar yang mampu mempengaruhi diri mereka daripada mengulangi jenayah tersebut lagi. Manakala, menerusi pemulihan dalam komuniti pula, pesalah juvana tidak ditempatkan di institusi pemulihan mahupun pusat koreksional, sebaliknya mereka dibenarkan untuk tinggal bersama dengan keluarga. Namun, pergerakan mereka akan sentiasa dipantau oleh pegawai yang dilantik khas oleh Jabatan Kebajikan Masyarakat Malaysia (JKMM). ${ }^{9}$ Walau bagaimanapun, fungsi sebenar institusi pemulihan dan pusat koreksional adalah menempatkan individu yang terlibat dengan pelbagai kes salah laku moral, bukan sahaja tertumpu kepada salah laku seksual. Namun, dalam makalah ini perbincangan memfokuskan kepada pesalah seks kerana berdasarkan kajian lepas, kes paling banyak yang menjadi punca remaja ditempatkan di institusi pemulihan sememangnya melibatkan kesalahan seksual. ${ }^{10}$

Oleh itu, makalah ini akan mengupas bentuk-bentuk pemulihan akhlak bagi pesalah seks di institusi pemulihan dan pusat koreksional di Malaysia berdasarkan kepada tinjauan terhadap kajian-kajian lepas. Kajian ini berbentuk kualitatif dengan menggunakan metode analisis deskriptif daripada hasil dapatan kajian-kajian yang lepas.

\section{Bentuk-bentuk Pemulihan Akhlak bagi Pesalah Seks di Institusi Pemulihan dan Pusat Koreksional di Malaysia}

Berdasarkan penelitian terhadap kajian-kajian lepas, secara ringkasnya memperlihatkan rata-rata bentuk pemulihan akhlak di institusi pemulihan dan pusat koreksional di Malaysia dapat dibahagikan kepada empat bentuk iaitu pemulihan berasaskan

9 Muhamad Razak Idris, beliau adalah Pensyarah Kanan di Fakulti Pengajian Islam, Universiti Kebangsaan Malaysia.

10 Khairul Hamimah Mohd. Jodi, "Penerapan Nilai-nilai Islam dalam Modul Pembangunan Wanita Bermasalah di Malaysia: Kajian di Wilayah Persekutuan Kuala Lumpur" (Tesis Kedoktoran, Universiti Malaya, Kuala Lumpur, 2013). 
keagamaan/kerohanian, pemulihan berasaskan bimbingan dan kaunseling Islam, pemulihan berasaskan pengintegrasian latihan vokasional dan pendidikan serta pemulihan berasaskan pembangunan fizikal dan sosial. Jadual 1 di bawah menjelaskan bentuk-bentuk pemulihan akhlak bagi pesalah seks di institusi pemulihan dan pusat koreksional di Malaysia:

Jadual 1: Bentuk-bentuk Pemulihan Akhlak bagi Pesalah Seks di Institusi Pemulihan dan Pusat Koreksional

\begin{tabular}{|c|c|}
\hline $\begin{array}{c}\text { Bentuk-bentuk Pemulihan } \\
\text { bagi Pesalah Seks }\end{array}$ & $\begin{array}{l}\text { Institusi Pemulihan } \\
\text { / Pusat Koreksional }\end{array}$ \\
\hline 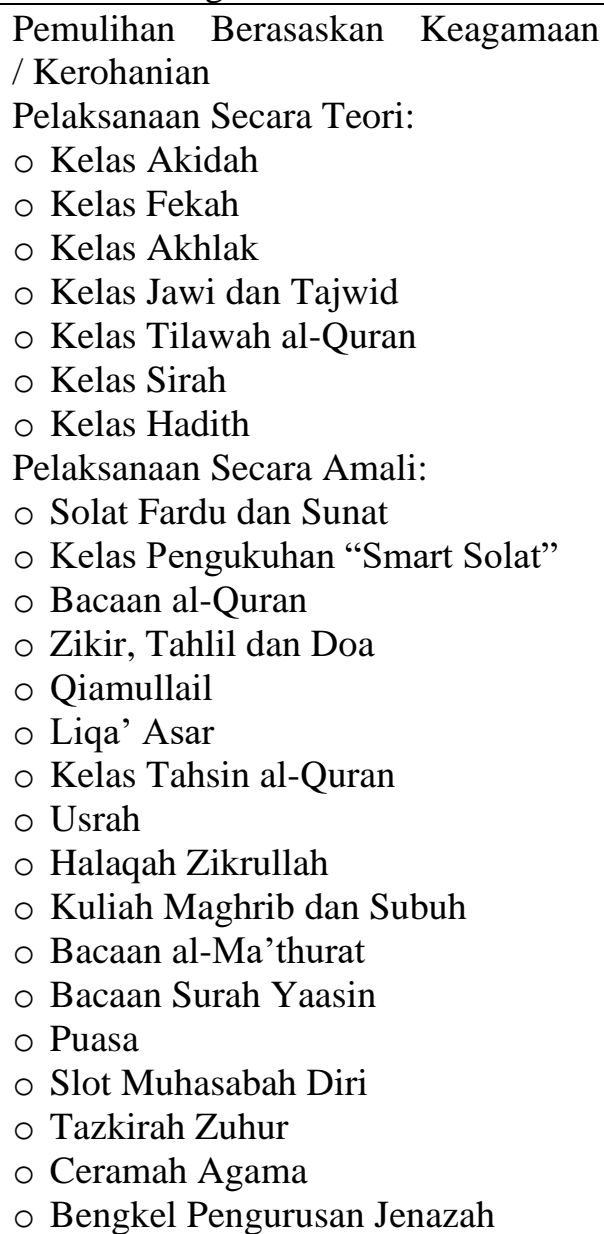 & $\begin{array}{l}\text { O Taman Seri Puteri } \\
\text { o Baitul Ehsan } \\
\text { O Kompleks Dar } \\
\text { Assaadah } \\
\text { O Darul Wardah } \\
\text { o Raudhatus Sakinah } \\
\text { ○ Jabatan Penjara } \\
\text { Malaysia }\end{array}$ \\
\hline
\end{tabular}




\begin{tabular}{|c|c|}
\hline $\begin{array}{l}\text { Program Dakwah: } \\
\text { o Program hari kebesaran Islam } \\
\text { berbentuk ceramah, forum dan } \\
\text { tazkirah seperti: } \\
\text { o Majlis Sambutan Maal Hijrah } \\
\text { O Majlis Sambutan Maulidur Rasul, } \\
\text { O Majlis Sambutan Isra' dan Mikraj } \\
\text { O Majlis Penghayatan Ramadan } \\
\text { o Nasyid }\end{array}$ & \\
\hline $\begin{array}{l}\text { Pemulihan Berasaskan Bimbingan dan } \\
\text { Kaunseling Islam }\end{array}$ & $\begin{array}{l}\text { O Taman Seri Puteri } \\
\text { - Kompleks Dar } \\
\text { Assaadah } \\
\text { o Darul Wardah } \\
\text { o Raudhatus Sakinah } \\
\text { - Baitul Ehsan }\end{array}$ \\
\hline $\begin{array}{l}\text { Pemulihan Berasaskan Pengintegra- } \\
\text { sian Latihan Vokasional dan } \\
\text { Pendidikan } \\
\text { o Kelas Jahitan } \\
\text { o Kelas Masakan } \\
\text { o Kelas Kraf Tangan } \\
\text { o Kelas Keusahawanan } \\
\text { o Kelas Pertanian } \\
\text { o Kelas Komputer } \\
\text { o Kelas Bahasa Inggeris dan Arab }\end{array}$ & $\begin{array}{l}\text { O Taman Seri Puteri } \\
\text { o Baitul Ehsan } \\
\text { O Kompleks Dar } \\
\text { Assaadah } \\
\text { O Darul Wardah } \\
\text { o Raudhatus Sakinah } \\
\text { O Jabatan Penjara } \\
\text { Malaysia }\end{array}$ \\
\hline $\begin{array}{l}\text { Pemulihan Berasaskan Pembangunan } \\
\text { Fizikal dan Sosial } \\
\text { o Rekreasi dan Ziarah } \\
\text { o Riadah dan Sukan } \\
\text { o Seni } \\
\text { o Gotong-royong } \\
\text { o Kawad Kaki } \\
\text { o Kem Motivasi } \\
\text { o Program Khidmat Masyarakat } \\
\text { o Lawatan Sambil Belajar } \\
\text { o Kursus Pra Perkahwinan } \\
\text { O Ceramah Kesihatan } \\
\text { o Kaunseling Individu } \\
\text { o Kaunseling Kelompok }\end{array}$ & $\begin{array}{l}\text { O Raudhatus Sakinah } \\
\text { O Baitul Ehsan } \\
\text { O Kompleks Dar } \\
\text { Assaadah } \\
\text { o Taman Seri Puteri } \\
\text { o Darul Wardah } \\
\text { o Jabatan Penjara } \\
\text { Malaysia }\end{array}$ \\
\hline
\end{tabular}




\section{Pemulihan Berasaskan Keagamaan / Kerohanian}

Pemulihan berasaskan keagamaan/kerohanian telah disediakan mengikut acuan agama Islam yang dianuti. Sebagai contohnya pengisian yang terdapat di dalam modul keagamaan seperti Modul Kurikulum Pendidikan Islam (Asas-asas Fardu Ain) yang dilaksanakan di Taman Seri Puteri (TSP) memfokuskan tiga aspek utama iaitu pengukuhan akidah, penghayatan ibadah dan pembangunan akhlak. ${ }^{11}$ Aspek-aspek tersebut mampu membantu proses pemulihan akhlak remaja melalui penekanan terhadap kepercayaan rukun iman dan rukun Islam seperti tuntutan menunaikan solat fardu secara berjemaah, berpuasa, membaca alQuran dan qiamullail. Natijahnya, perkara tersebut bukan sahaja mampu melahirkan rasa takut, cinta dan harap kepada Tuhan sehingga mendorong manusia sentiasa berwaspada untuk melakukan maksiat, bahkan ia juga mampu memberikan kesan positif terhadap kekuatan fizikal dan jiwa individu yang terjebak dengan salah laku seksual ini. ${ }^{12}$

Kenyataan ini turut disokong oleh Fariza Md Sham et al., di dalam kajiannya bahawa modul pendidikan rohani yang diimplementasikan terhadap remaja bermasalah memberi kesan yang positif terhadap psikologi dan kerohanian mereka dari aspek akidah, ibadat dan akhlak (nilai-nilai moral). ${ }^{13}$ Merujuk kepada pengisian keagamaan di institusi pemulihan akhlak dan pusat koreksional didapati dijalankan secara teori dan juga amali. Hasil penelitian mendapati bahawa kesemua enam institusi pemulihan dan pusat koreksional seperti yang dinyatakan di dalam jadual 1 mengimplementasikan pendekatan keagamaan/kerohanian terhadap pesalah seks sebagai salah satu metode pemulihan akhlak. Secara teorinya, aktiviti pengajaran dan pembelajaran agama disampaikan

11 Nurul Husna Mansor, "Modul Keagamaan untuk Remaja Hamil Luar Nikah", 225-250. Noor Hafizah Mohd Haridi, "Program Agama di Institusi Pemulihan Akhlak Jabatan Kebajikan Masyarakat (JKM): Kajian dari Aspek Pelaksanaan dan Keberkesanan" (Tesis Kedoktoran, Universiti Malaya, Kuala Lumpur, 2016), 116.

12 Nurul Husna Mansor et al., "Implementasi Ibadah Islam Sebagai Terapi Salah Laku Seksual Remaja: Kajian Terhadap Pusat Perlindungan Wanita Terpilih di Selangor," International Journal of Malay World and Civilisation (IMAN) 4, no. 1 (2016), 73-84.

13 Fariza Md Sham et al., "Spiritual Education Module for Out-of-Wedlock Pregnant Adolescents," Turkish Online Journal of Educational Technology (2015), 484-490. 
menerusi kelas pengajian fardu ain. Para pelatih diwajibkan untuk mempelajari beberapa subjek utama iaitu subjek akidah, ibadah, adab, fiqh, fiqh wanita, jawi, tajwid, iqra', tilawah al-Quran, hafazan, sirah nabawiyah dan hadis. ${ }^{14}$ Pendidikan akhlak yang dipelajari menerusi pembelajaran subjek adab menekankan adabadab terhadap keluarga, ilmu, al-Quran dan kehidupan mampu membentuk peribadi dan jati diri para pelatih yang terpuji jika dipraktikkan secara berterusan. ${ }^{15}$

Dalam konteks amali pula, pengukuhan dan penghayatan ibadah di kebanyakan institusi pemulihan dilaksanakan melalui praktikal solat-solat fardu dan sunat secara berjemaah, puasa, bacaan al-ma'thürat dan doa-doa harian, amalan zikir dan selawat, tazkirah zuhur, kuliah subuh dan maghrib, liqā̄' asar, qiamullail, slot muhasabah diri, program halaqah, usrah, praktikal mandi wajib, tayamum dan pengurusan jenazah. ${ }^{16}$ Sebagai contohnya, kelas pengukuhan solat yang dinamakan sebagai "Smart Solat" diadakan pada setiap minggu kepada semua pelatih di Pusat Perlindungan Wanita Baitul Ehsan (BES). Kelas pengukuhan solat tersebut bertujuan untuk mengukuhkan pemahaman pelatih mengenai solat bermula daripada mengambil wuduk sehingga perkara rukhsah dalam solat. ${ }^{17}$ Sesungguhnya, ibadah solat merupakan tiang agama yang menjadi benteng diri manusia daripada melakukan maksiat dan kemungkaran. Hal ini bertepatan dengan firman Allah SWT:

14 Nurul Husna Mansor et al., "Pemulihan Akhlak di Pusat Perlindungan Wanita," 261-274. Siti Marziah Zakaria dan Nur Afifah Zulkifli, "Pengalaman Remaja di Rumah Perlindungan dan Perubahan dalam Makna Hidup," Journal of Social Sciences and Humanities (2017), 1-11. Noor Hafizah Mohd Haridi, "Program Agama di Institusi Pemulihan Akhlak Jabatan Kebajikan Masyarakat (JKM)," 120-125. Khairul Hamimah Mohammad Jodi et al., "Program Koreksi Berasaskan Islam Melalui Program Halaqah Sebagai Medium Dakwah kepada Banduan di Penjara Kajang,” Jurnal Al-Hikmah (2015), 3-22.

15 Khairul Hamimah Mohammad Jodi dan Nurul Husna Mansor, "Penerimaan Remaja Terlanjur Terhadap Pengisian Kerohanian di Institusi Perlindungan Wanita" (kertas kerja pembentangan, 2nd International Conference on Religion and Society 2017, Universiti Malaysia Sabah, 2017).

16 Siti Marziah dan Nur Afifah, "Pengalaman Remaja di Rumah Perlindungan," 111. Nurul Husna Mansor et al., "Pemulihan Akhlak di Pusat Perlindungan Wanita," 261-274.

17 Modul Transformasi Ehsan, BES. 


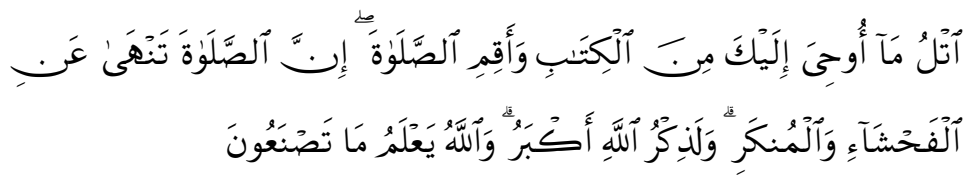

Al-'Ankābūt 29:45

Terjemahan: Bacalah serta ikutlah (wahai Muhammad) akan apa yang diwahyukan kepadamu dari al-Quran dan dirikanlah sembahyang (dengan tekun); sesungguhnya sembahyang itu mencegah dari perbuatan yang keji dan mungkar; dan sesungguhnya mengingati Allah adalah lebih besar (faedahnya dan kesannya); dan (ingatlah) Allah mengetahui akan apa yang kamu kerjakan.

Di samping itu, kajian oleh Zaizul Abd Rahman et al. juga mendapati bahawa pendekatan keagamaan yang dilaksanakan di penjara telah berjaya menarik minat banduan untuk menyertainya. ${ }^{18}$ Hal yang demikian terbukti apabila majoriti pesalah jenayah rogol di Penjara Sungai Udang, Melaka bersetuju bahawa pendekatan keagamaan merupakan pendekatan yang amat bermanfaat dan paling memberikan kesan yang mendalam kepada mereka. Natijah daripada pendekatan pemulihan tersebut mampu membina keyakinan diri mereka untuk menjalani kehidupan bermasyarakat selepas mereka dibebaskan kelak. Perkara tersebut disokong juga oleh kajian yang dijalankan oleh Siti Jamiaah et al. terhadap banduan wanita di lima buah penjara terpilih di Malaysia membuktikan bahawa pendekatan keagamaan mampu membangunkan psikologi dan konsep kendiri banduan wanita yang lebih positif dan seimbang. ${ }^{19}$ Begitu juga kajian Azhar Yaakub et al., yang menekankan bahawa pendekatan agama dan nilai moral yang terkandung di dalam program pendidikan merupakan antara pendekatan yang proaktif dilaksanakan bagi pesalah seks remaja. ${ }^{20}$

18 Zaizul Abd Rahman et al., "Program Pemulihan Insan dalam Kalangan Banduan Melayu di Penjara Sungai Udang, Melaka" (Kertas kerja, International Conference On Islamic Civilization and Malay Identity 2011 (ICICMI2011), Equatorial Hotel Melaka, Melaka, Malaysia, 14-15 November, 2011).

19 Siti Jamiaah Abdul Jalil, Yusmini Md Yusoff dan Rozmi Ismail, "Peranan Program Keagamaan Terhadap Pemulihan Konsep Kendiri Banduan Wanita di Malaysia," Jurnal al-Afkar 18, no. 2 (2016), 193-228.

20 Azahar Yaakub et al., "Pendekatan Program Pendidikan ke atas Remaja Hamil Luar Nikah," International Journal of Islamic Studies (Al-Qanatir) 8, no. 3 (2017), 24-31. 
Perkara ini juga selaras dengan program pemulihan melalui sistem pendidikan di sekolah bagi pesalah juvana yang bertujuan untuk memperbaiki dan mengukuhkan akhlak. ${ }^{21}$

Selain itu, sambutan hari kebesaran Islam seperti Awal Muharam, Nuzul Quran, majlis sambutan Maal Hijrah, majlis sambutan Maulidur Rasul, majlis sambutan Isra' dan Mikraj, marhaban, majlis khatam al-Quran, majlis tadarus al-Quran pada bulan Ramadan dan sebagainya merupakan antara program dakwah yang giat dijalankan oleh institusi pemulihan akhlak terutamanya di Darul Wardah, Kompleks Dar Assaadah dan Taman Seri Puteri. ${ }^{22}$ Pertandingan Tilawah al-Quran dan nasyid juga diadakan di peringkat pusat. Pengisian tersebut kebiasaannya diadakan pada waktu tertentu dan disampaikan dalam bentuk ceramah, forum dan tazkirah. Pengisian yang disampaikan secara tidak langsung berupaya mencambahkan ilmu pengetahuan para pelatih tentang Islam sekali gus mampu menjadi pengikat hubungan persaudaraan antara muslim.

Sesungguhnya, Islam merupakan agama yang membawa kesejahteraan dan keselamatan dalam kehidupan umat manusia. Pemeliharaan terhadap maslahah manusia amat dititikberatkan dan mesti dijaga dengan sebaik mungkin seperti yang dinyatakan dalam prinsip Maqasid Syariah. Walaupun begitu, Islam turut melarang umatnya daripada melakukan perkara-perkara yang boleh memudaratkan dan mendatangkan mafsadah kepada diri. Justeru, bagi memperoleh kemanfaatan dan menghindarkan kerosakan dalam rangka memelihara tujuan syarak, maka Islam telah menggariskan lima perkara utama yang disebut sebagai darüriyyāt al-khams iaitu menjaga agama, nyawa, akal, keturunan dan harta. ${ }^{23}$ Perkara ini bertepatan dengan saranan pemulihan dalam Islam yang menekankan penjagaan dari aspek fizikal dan spiritual manusia

21 Darussalam Budin, "Pendidikan Juvana di Jabatan Penjara Malaysia: Dasar, Hala Tuju, Pelaksanaan dan Cabaran," Jurnal Hadhari 6, no. 1 (2014), 87-104.

22 Khairul Hamimah dan Nurul Husna, "Penerimaan Remaja Terlanjur," 2017. Noor Hafizah, "Program Agama di Institusi Pemulihan Akhlak," 2016.

23 Wan Muhammad Naif Mohd Nordin dan Ahmad Dahlan Salleh, "Siasah Syar'iyyah Sebagai Mekanisma Penjagaan Akal," Jurnal Pengajian Islam, no. 10 (2017), 111-126. 
secara bersesuaian dengan peranan setiap komponen agar ia dapat berfungsi dengan baik dan konsisten. ${ }^{24}$

\section{Pemulihan Berasaskan Bimbingan dan Kaunseling Islam}

Selain menumpukan kepada pemulihan berasaskan keagamaan/kerohanian, pemulihan berasaskan bimbingan dan kaunseling Islam juga telah banyak digunakan di institusi pemulihan sebagai salah satu metode utama dalam usaha membendung masalah penyelewengan tingkah laku dalam kalangan remaja khususnya yang melibatkan kes salah laku seksual. Misalnya, pendekatan kaunseling psikologi kognitif Ad-Dīn memberikan kesan yang positif dalam meningkatkan keyakinan diri dan daya tahan remaja yang terlibat dengan salah laku seksual. Bukan itu sahaja, bahkan ia juga telah berjaya mengurangkan masalah kemurungan yang dihadapi oleh remaja tersebut. ${ }^{25} \mathrm{Hal}$ ini turut diperakui oleh Salasiah Hanin Hamjah et al. yang menggalakkan ibu bapa agar mendapatkan perkhidmatan kaunseling dalam mendidik anak-anak remaja terutamanya bagi remaja yang terlibat dengan masalah salah laku seksual. ${ }^{26}$ Tambahan lagi, pendekatan Islam dalam kaunseling yang merangkumi tiga aspek utama iaitu akidah, ibadah dan akhlak sememangnya dilihat berpotensi dalam membantu remaja yang bermasalah. $^{27}$

Selain itu, satu modul yang dikenali sebagai modul Kaunseling Pendekatan Islam berdasarkan Pendekatan Amar Makruf Nahi Mungkar (AMAR) telah dibangunkan secara khusus bagi menangani masalah penyelewengan tingkah laku seksual pelajar. ${ }^{28}$

24 Zaizul Abd Rahman et al., "Program Pemulihan Insan dalam Kalangan Banduan Melayu di Penjara Sungai Udang, Melaka," 2011.

25 Fauziah Mohd Sa'ad et al., "The Effectiveness of Person-Centered Theraphy and Cognitive Psychology Ad-Din Group Counseling on Self-Concept, Depression and Resilience of Pregnant Out-of Wedlock Teenagers," Procedia - Social and Behavioral Sciences, (2014), 927-932.

26 Salasiah Hanin Hamjah et al., "The Role of the Muslim Family in Dealing with Adolescent Out-of-Wedlock Pregnancy," Mediterranean Journal of Social Sciences, (December 2014), 101-106.

27 Salasiah Hanin Hamjah dan Noor Shakirah Mat Akhir, "Islamic Approach in Counseling," Journal of Religion and Health (2014), 279-289.

28 Roslee Ahmad et al., "Strategi Intervensi Menangani Penyelewengan Tingkah Laku Seksual Berdasarkan Model Al Ghazalī.” (Kertas kerja, Persidangan 
Melalui pendekatan ini, kaunselor-kaunselor Islam berpandangan bahawa lapan strategi modul al-Ghazālī yang menekankan aspek akidah, akhlak dan syariat Islam dilihat mampu menjadi benteng dan perisai kepada remaja agar tidak terjebak dengan penyelewengan tingkah laku seksual. Hasil penelitian mendapati pendekatan bimbingan dan kaunseling Islam ini telah dijalankan di Taman Seri Puteri, Kompleks Dar Assaadah, Darul Wardah, Baitul Ehsan dan Raudhatus Sakinah.

Walaupun pendekatan ini dikenal pasti telah lama diguna pakai dalam proses pemulihan akhlak pesalah seks, namun ia masih dijalankan di institusi pemulihan sehingga sekarang. Di samping itu, kajian yang dijalankan oleh Nurdeng Deuraseh dan Amaludin Ab. Rahman, mendapati bahawa pendekatan kaunseling keagamaan amat signifikan dilaksanakan terhadap golongan pesalah seks. ${ }^{29}$ Rata-rata pesalah seks yang dijangkiti HIV dan AIDS akibat daripada hubungan seks bebas yang dilakukan mengakui bahawa aspek keagamaan dan kesejahteraan rohani dalam kaunseling mampu mencegah seseorang individu itu daripada terlibat dengan gejala seksual. Bukan itu sahaja, saranan oleh Khairiyah Md. Shahid et al. agar anak-anak remaja diberikan pendedahan awal berkenaan modul kaunseling kesihatan yang mengandungi maklumat tentang pendidikan seksual juga harus disahut. ${ }^{30}$

\section{Pemulihan Berasaskan Pengintegrasian Latihan Vokasional dan Pendidikan}

Aktiviti pembangunan kemahiran sosial yang tertumpu kepada latihan vokasional dan kelas kemahiran seperti kelas kemahiran berbahasa Inggeris dan berbahasa Arab, jahitan, masakan, kraf tangan, keusahawanan, pertanian dan komputer turut dijalankan

Kaunseling Kebangsaan 2009, Palace of The Golden Horses, Serdang, Selangor, 3-5 November, 2009).

${ }^{29}$ Nurdeng Deuraseh dan Amaludin Ab. Rahman, "Pendekatan Keagamaan dan Kesejahteraan Rohani Teras Pencegahan HIV \& AIDS: Perspektif Responden HIV/AIDS," Jurnal Islam dan Masyarakat Kontemporari 8, (Jun 2014), 1-19.

30 Khairiyah Hj Md. Shahid et al., "Adolescents and Premarital Sex: Perspectives from Family Ecological Context," International Journal for Studies on Children, Women, Elderly and Disabled 1, (2017), 157-165. 
sebagai salah satu platform pemulihan pesalah seks. ${ }^{31}$ Latihan vokasional ini didapati dilaksanakan di Kompleks Dar Assaadah, Baitul Ehsan, Taman Seri Puteri, Raudhatus Sakinah, Darul Wardah dan Jabatan Penjara Malaysia. Sebagai contohnya, kelas kemahiran menjahit yang ditawarkan di Kompleks Dar Assaadah (KDS) mampu mendidik nilai disiplin dalam diri para pelatih melalui pengendalian peralatan jahitan dan kaedah menjahit. Bukan itu sahaja, ia juga berupaya memberikan kepakaran dan nilai tambah kepada diri mereka sekaligus mengisi masa lapang dengan kegiatan yang berfaedah. ${ }^{32}$ Aktiviti pertandingan memasak, kraf tangan dan menjahit juga diadakan bertujuan untuk mengasah bakat dan menilai tahap penguasaan mereka terhadap kemahiran yang dipelajari.

Di samping itu, melalui kelas vokasional masakan, para pelatih bukan sahaja diajar kaedah memasak secara teori dan praktikal, malah kaedah masakan secara Islam turut diterapkan dalam pengamalan latihan masakan. Misalnya para pelatih diajar berkaitan cara memilih, membersih dan memotong bahan makanan dengan teknik yang betul, menjaga aurat semasa memasak, memasang niat serta membaca doa dan selawat sebelum memulakan masakan. ${ }^{33}$ Menurut Abdul Rashed Ebrahim, setiap pekerjaan yang hendak dilakukan mestilah dimulakan dengan niat kerana dengan niat, perkara tersebut dapat melahirkan amal yang baik. ${ }^{34}$ Begitu juga dalam konteks memulakan aktiviti memasak, ia mestilah diniatkan untuk mendapatkan keredaan dan rahmat Allah SWT. Amalan kebersihan juga menjadi aspek utama yang dititikberatkan dalam kelas masakan. Latihan vokasional yang dijalankan di institusi pemulihan bukan sahaja mampu meningkatkan pendedahan diri, kesedaran sosial, harga diri, empati dan pengurusan pemikiran

31 Nurul Husna Mansor et al., "Pemulihan Akhlak di Pusat Perlindungan Wanita: Kajian di Baitul Ehsan dan Dar Assaadah," Jurnal Hadhari 9, no. 2 (2017), 261274.

32 Silibus Dar Assaadah-Kelas Kemahiran (Jahitan) (Kuala Lumpur: Majlis Agama Islam Wilayah Persekutuan, t.t.).

33 Ahmad Esa, Zalina @ Siti Aishah Abdul Aziz dan Nurul Haerani Mohamad, "Pengintegrasian Latihan Vokasional Masakan dan Pendidikan Islam dalam Kalangan Remaja Terlanjur di Pusat Pemulihan Akhlak Remaja," Jurnal Kajian Pendidikan 4, no. 1 (2014), 47-60.

34 Abdul Rashed Ebrahim, Permata Hadis Empat Puluh Pedoman Hidup Muslim (Kuala Lumpur: Pustaka al-Shafa, 2011). 
devian pesalah, ${ }^{35}$ bahkan ia telah memberi peluang kepada pelatih untuk mendapatkan ilmu serta kemahiran yang berkaitan untuk digunakan selepas tamat tempoh penahanan kelak.

Selain pemulihan berasaskan pengintegrasian latihan vokasional, perkhidmatan pemulihan bagi pesalah juvana juga didapati dilaksanakan melalui pendidikan di pusat koreksional atau lebih dikenali sebagai penjara. Penjara bukan sahaja berperanan sebagai sebuah institusi pemulihan dan keselamatan bagi para banduan, malah ia juga bertanggungjawab memberikan pendidikan kepada mereka. Justeru, bagi tujuan menampung keperluan pendidikan juvana secara menyeluruh, Jabatan Penjara Malaysia (JPM) dengan kerjasama Kementerian Pelajaran Malaysia (KPM) telah mewujudkan sistem persekolahan secara formal pada tahun 2008. Semua sekolah ini dibina di dalam kawasan penjara melalui pengubahsuaian bangunan sedia ada. Sekolah ini dihuni oleh 'pelajar khas' yang terdiri daripada banduan muda iaitu mereka yang dijatuhi hukuman oleh mahkamah kerana melakukan pelbagai kesalahan jenayah. ${ }^{36}$ Sekolah di dalam penjara ini menyediakan proses pembelajaran kepada juvana yang tidak lagi bersekolah di aliran perdana. Perkara tersebut memberikan peluang kedua dan harapan kepada penghuninya untuk membina masa hadapan yang lebih cerah.

Antara jenis-jenis sistem persekolahan yang dikenal pasti ialah Sekolah Tunas Bakti di bawah Jabatan Kebajikan Masyarakat Malaysia (JKMM), Sekolah Henry Gurney dan Sekolah Integriti di bawah Jabatan Penjara Malaysia (JPM) serta Sekolah Agama Tarbiyah Husnul Khatimah di bawah Majlis Agama Islam Johor (MAIJ). Sekolah Integriti merupakan sekolah untuk menempatkan juvana yang ditahan di bawah Akta Langkah-Langkah Pencegahan Khas Dadah 1985 dan juvana yang ditahan atau disabitkan selain dari Akta Kanak-Kanak 2000, manakala Sekolah Henry Gurney pula menempatkan juvana yang disabitkan kesalahan oleh

35 Jerry L. Jennings, dan Adam Deming, "Effectively Utilizing the "Behavioral" in Cognitive-Behavioral Group Therapy of Sex Offenders," International Journal of Behavioral Consultation and Therapy 8, no. 2 (2013), 7-13.

36 Jabatan Penjara Malaysia, Pekeliling Sektor Pendidikan Jabatan Penjara Malaysia: Dasar, Objektif dan Halatuju Pendidikan di Jabatan Penjara Malaysia (t.tp.: t.p., 2009). 
Mahkamah Kanak-Kanak melalui Akta Kanak-Kanak 2001.37 Menerusi program pemulihan di Sekolah Agama Tarbiah Husnul Khatimah, para banduan diberi peluang menghafal al-Quran dan mendalami ilmu-ilmu agama dengan lebih baik melalui program Tahfiz al-Quran dan kelas fardu ain yang dijalankan. ${ }^{38}$

Secara umumnya, program pemulihan di sekolah penjara bertujuan memberikan pendidikan formal dan memperbaiki nilainilai murni penghuni supaya mereka dapat diterima semula oleh masyarakat. Namun, secara khususnya matlamat pendidikan untuk juvana adalah bertujuan memperbaiki dan mengukuhkan akhlak, memberikan peluang bagi memulakan dan meneruskan persekolahan, menimbulkan minat untuk belajar dan meyakinkan pelajar bahawa pendidikan dapat menjamin masa hadapan yang lebih baik. ${ }^{39}$ Pelaksanaan aktiviti pendidikan di sekolah penjara pula diselia oleh Sektor Pendidikan di bawah Seksyen Pemulihan dan Rawatan, Bahagian Pengurusan Banduan. Terdapat dua jenis aliran yang disediakan di sekolah penjara iaitu aliran akademik dan aliran kemahiran. Walau bagaimanapun, pemilihan aliran sama ada aliran akademik atau aliran kemahiran akan ditentukan melalui beberapa peringkat saringan.

Dalam konteks negara Malaysia, para banduan yang sedang melalui proses pemenjaraan perlu mengikuti satu siri program hukuman dan pemulihan sosial berasaskan institusi yang dikenali sebagai Pelan Pembangunan Insan (PPI). PPI yang diperkenalkan pada tahun 2002 ini merupakan satu program pemulihan sosial yang menekankan proses pembentukan disiplin dan sahsiah diri penghuni penjara. Di dalam program ini, terdapat empat fasa yang perlu dilalui oleh setiap banduan iaitu Fasa Pembentukan Disiplin, Fasa Pengukuhan Sahsiah, Fasa Kemahiran dan Fasa Pemasyarakatan. Menerusi fasa Pengukuhan Sahsiah, terdapat empat program utama yang menjadi teras dalam proses pemulihan pesalah iaitu Program Terapeutik Komuniti, Program Halāqah, Program Pendidikan dan

37 Jabatan Penjara Malaysia, Pekeliling Sektor Pendidikan Jabatan Penjara Malaysia: Dasar, Objektif dan Halatuju Pendidikan di Jabatan Penjara Malaysia.

38 Hasnizam Hashim, Norman Zakiyy Chow Jen T'Ciang dan Ramalinggam Rajamanickam, "Program Pemulihan di dalam Penjara bagi Pesalah Jenayah: Kajian di Jabatan Penjara Malaysia," Jurnal Undang-undang dan Masyarakat (JUUM) (2018), 72-85.

39 Jabatan Penjara Malaysia, 2009. 
Bimbingan serta Program Akademik. Keempat-empat fasa ini turut dilaksanakan dan ditekankan kepada juvana di sekolah penjara.

Namun, dalam fasa Pengukuhan Sahsiah untuk juvana, suatu modul yang dikenali sebagai Modul Putra telah digunakan. Modul ini berasaskan pendidikan yang hampir sama dengan Kurikulum Bersepadu Sekolah Menengah, Kementerian Pelajaran Malaysia. ${ }^{40}$ Melalui Program Pendidikan dan Bimbingan pula, lima buah kelas telah diwujudkan bertujuan untuk mengasah kemahiran membaca, mengira dan menulis pelajar sekaligus menghapuskan kadar buta huruf dalam kalangan mereka. Selain itu, ia juga merupakan kelas persediaan bagi pelajar yang bakal menduduki peperiksaan Penilaian Menengah Rendah (PMR) dan Sijil Pelajaran Malaysia (SPM). Kelas-kelas tersebut ialah 3M (membaca, mengira dan menulis), kelas Pra PMR, kelas PMR, kelas Pra SPM dan kelas SPM. Secara ringkasnya, jika diperhatikan bentuk pendekatan pemulihan akhlak yang digunakan dalam tempoh lima tahun terkini iaitu pada tahun 2014 sehingga 2019 lebih tertumpu kepada pendekatan keagamaan, pendekatan bimbingan dan kaunseling, program vokasional, program kokurikulum dan program berbentuk pendidikan.

Hakikatnya, pemulihan secara pendidikan dapat membantu memulihkan pesalah dari segi tingkah laku, kemahiran hidup dan membina keyakinan diri supaya mereka dapat berhadapan dengan masyarakat apabila dibebaskan daripada institusi pemulihan kelak. Pendidikan melalui sistem persekolahan juga merupakan elemen yang sangat penting kepada sesebuah negara dalam usaha membangunkan masyarakat yang cemerlang dari pelbagai aspek kehidupan. Sistem persekolahan bukan sahaja berperanan memberikan pelajaran dan pengajaran kepada masyarakat sematamata, bahkan ia juga berfungsi sebagai wadah bagi menyampaikan kepentingan nilai-nilai murni dalam kalangan masyarakat demi mencapai kesejahteraan dan perpaduan sejagat. ${ }^{41}$

40 Jabatan Penjara Malaysia, Sinar Keinsafan (Kajang: Penerbitan Jabatan Penjara Malaysia, 2010).

41 Mior Khairul Azrin Mior Jamaluddin, "Sistem Pendidikan di Malaysia: Dasar, Cabaran dan Pelaksanaan ke Arah Perpaduan Nasional," Jurnal Sosiohumanika 4, no. 1 (2011), 33-47. 


\section{Pemulihan Berasaskan Pembangunan Fizikal dan Sosial}

Menelusuri perbincangan mengenai pemulihan berasaskan pembangunan fizikal dan sosial, aktiviti-aktiviti seperti rekreasi, riadah, senamrobik, sukan, gotong-royong dan kawad kaki juga menjadi salah satu platform yang penting dalam proses pemulihan akhlak pelatih. ${ }^{42}$ Contohnya aktiviti riadah dan rekreasi yang dilaksanakan di Raudhatus Sakinah dan Darul Wardah membantu pelatih merehatkan minda, bahkan aktiviti sebegini bukan sahaja berupaya melahirkan tubuh badan yang sihat dan akal yang cerdas, malah mampu menyemai akhlak mulia dalam diri pelatih. Hal ini bertepatan dengan pepatah arab yang berbunyi 'akal yang sihat datang daripada tubuh badan yang sihat'. Begitu juga dengan aktiviti kawad kaki berupaya membentuk sikap yang positif seperti tekun, disiplin dan fokus dalam menjalankan tanggungjawab sebagai seorang Muslim.

Di samping itu, kaunseling individu dan kaunseling kelompok juga turut dijalankan sebagai salah satu program pemulihan akhlak bagi pesalah seks. Menurut Myers, beliau telah memperkenalkan sebuah program kaunseling berkumpulan yang dikenali sebagai Roda Kesejahteraan. Program ini merangkumi program kerohanian, haluan tuju diri, program masa lapang dan program berkasih sayang. Program kerohanian dilaksanakan bagi merawat diri pesalah juvana melalui penyucian dalaman atau pemulihan jiwa dan rohani individu. Program ini merangkumi terapi agama yang melibatkan aktiviti seperti menunaikan ibadat solat, berbuat amal kebajikan dan pendidikan moral. ${ }^{43}$ Selain itu, terdapat juga aktiviti sosial dan kemasyarakatan yang lain seperti kem motivasi, program khidmat masyarakat, lawatan sambil belajar dan sebagainya.

Tambahan lagi, penguatkuasaan peraturan daripada aspek pakaian, pergaulan dan kawalan sosial yang dilaksanakan menjadikan pelatih sentiasa berusaha berkelakuan baik agar tidak didenda dan dihukum. Berpakaian sopan dan menutup aurat juga mampu menyemai benih-benih akhlak Islam dalam diri para pelatih. Tidak kurang juga peraturan larangan menggunakan

42 Nurul Husna Mansor et al., "Pemulihan Akhlak di Pusat Perlindungan Wanita," 261-274.

43 J. E. Myers, T. J. Sweeney, and J. A Witner, "The Wheel of Wellness Counseling for Wellness: A Holistic Model for Treatment Planning," Journal of Counseling and Development 78 (2000), 251-266. 
sebarang jenis media sosial dan peralatan komunikasi seperti telefon bimbit dan internet sepanjang tempoh pemulihan dapat membantu pelatih mengawal diri mereka daripada terjebak dengan penyalahgunaan kemudahan teknologi sedia ada. Tambahan pula, perkara tersebut mampu menjuruskan tumpuan para pelatih sepenuhnya terhadap program pemulihan yang dijalankan. Kawalan keluar masuk penghuni daripada institusi pemulihan dan pusat koreksional juga diperketatkan seperti yang diimplementasikan di Pusat Perlindungan Wanita Baitul Ehsan (BES), Kompleks Dar Assaadah (KDS) dan Jabatan Penjara Malaysia (JPM). ${ }^{44}$

Secara kesimpulannya, trend penulisan mengenai bentuk pemulihan akhlak bagi pesalah seks di Malaysia dalam tempoh lima tahun terkini bermula tahun 2015 sehingga 2019 lebih memberikan penekanan kepada pemulihan berasaskan keagamaan/kerohanian serta pemulihan berasaskan latihan vokasional dan pendidikan. Pemulihan berasaskan bimbingan dan kaunseling pula dikenalpasti telah lama diguna pakai dalam proses pemulihan akhlak pesalah seks hatta sehingga sekarang pun ia masih dilaksanakan. Walau bagaimanapun, perbincangan tersebut lebih tertumpu kepada perkhidmatan kaunseling individu dan kelompok. Namun bagi tempoh 10 tahun terkini, perbincangan mengenai pemulihan berasaskan bimbingan dan kaunseling Islam didapati diberikan perhatian dan penekanan dalam proses pemulihan akhlak pesalah seks di rata-rata institusi pemulihan di Malaysia. Tambahan lagi, kajian mendapati rata-rata penyelidik daripada bidang sains sosial telah banyak membincangkan tentang pemulihan, psikologi dan pendidikan bagi golongan pesalah seks ini.

\section{Penutup}

Berdasarkan kepada perbincangan di atas, dapat disimpulkan bahawa rata-rata bentuk pemulihan di institusi pemulihan dan pusat koreksional lebih tertumpu kepada pemulihan berasaskan keagamaan/kerohanian, pemulihan berasaskan bimbingan dan kaunseling Islam, pemulihan berasaskan pengintegrasian latihan vokasional dan pendidikan serta pemulihan berasaskan pembangunan fizikal dan sosial. Walau bagaimanapun, peranan

44 J. E. Myers, T. J. Sweeney, and J. A Witner, "The Wheel of Wellness Counseling for Wellness: A Holistic Model for Treatment Planning," Journal of Counseling and Development 78 (2000), 251-266. 
program pemulihan bukan sahaja menyokong proses merawat dan membaik pulih pesalah seks dari aspek fizikal, mental, rohani dan jasmani, malah ia juga berusaha membantu mengembalikan semula pesalah terbabit kepada kehidupan yang diredai oleh Allah SWT. Hal yang demikian kerana fitrah diri setiap manusia adalah berhajat kepada agama bagi menjamin keselamatan dan kesejahteraan hidup yang berpanjangan di dunia dan di akhirat.

\section{Penghargaan}

Kajian ini telah dibiayai oleh dana Geran Bantuan Kecil Penyelidikan (BKP) BK003-2018 Universiti Malaya. Penghargaan ditujukan kepada mereka yang telah menjayakan projek ini.

\section{Rujukan}

Abdul Rashed Ebrahim. Permata Hadis Empat Puluh Pedoman Hidup Muslim. Kuala Lumpur: Pustaka al-Shafa, 2011.

Ahmad Esa, Zalina @ Siti Aishah Abdul Aziz dan Nurul Haerani Mohamad. "Pengintegrasian Latihan Vokasional Masakan dan Pendidikan Islam dalam Kalangan Remaja Terlanjur di Pusat Pemulihan Akhlak Remaja." Jurnal Kajian Pendidikan 4, no. 1 (2014), 47-60.

Akta Kanak-Kanak 2001 (Akta 611).

Azahar Yaakub et al. "Pendekatan Program Pendidikan ke atas Remaja Hamil Luar Nikah." International Journal of Islamic Studies (Al-Qanatir) 8, no. 3 (2017), 24-31.

Darussalam Budin. "Pendidikan Juvana di Jabatan Penjara Malaysia: Dasar, Hala Tuju, Pelaksanaan dan Cabaran." Jurnal Hadhari 6, no. 1 (2014), 87-104.

Fariza Md Sham et al. "Spiritual Education Module for Out-ofWedlock Pregnant Adolescents." Turkish Online Journal of Educational Technology (2015), 484 - 490.

Fauziah Mohd Sa'ad et al. "The Effectiveness of Person-Centered Theraphy and Cognitive Psychology Ad-Din Group Counseling on Self-Concept, Depression and Resilience of Pregnant Out-of Wedlock Teenagers." Procedia - Social and Behavioral Sciences (2014), 927-932.

Hasnizam Hashim, Norman Zakiyy Chow Jen T'Ciang dan Ramalinggam Rajamanickam. "Jenayah: Kajian di Jabatan 
Penjara Malaysia." Jurnal Undang-undang dan Masyarakat (JUUM) (2018), 72-85.

J. E. Myers, T. J. Sweeney, and J. A Witner. "The Wheel of Wellness Counseling for Wellness: A Holistic Model for Treatment Planning." Journal of Counseling and Development 78 (2000), 251-266.

Jabatan Penjara Malaysia, Pekeliling Sektor Pendidikan Jabatan Penjara Malaysia: Dasar, Objektif dan Halatuju Pendidikan di Jabatan Penjara Malaysia. T.tp.: t.p., 2009.

Jabatan Penjara Malaysia. Sinar Keinsafan. Kajang: Penerbitan Jabatan Penjara Malaysia, 2010.

Jerry L. Jennings dan Adam Deming. "Effectively Utilizing the "Behavioral" in Cognitive-Behavioral Group Therapy of Sex Offenders." International Journal of Behavioral Consultation and Therapy 8, no. 2 (2013), 7-13.

Khairiyah $\mathrm{Hj} \mathrm{Md}$. Shahid et al. "Adolescents and Premarital Sex: Perspectives from Family Ecological Context." International Journal for Studies on Children, Women, Elderly and Disabled 1 (2017), 157-165.

Khairul Hamimah Mohammad Jodi dan Nurul Husna Mansor. "Penerimaan Remaja Terlanjur Terhadap Pengisian Kerohanian di Institusi Perlindungan Wanita." Kertas kerja pembentangan, 2nd International Conference on Religion and Society 2017, Universiti Malaysia Sabah, 2017.

Khairul Hamimah Mohammad Jodi et al. "Program Koreksi Berasaskan Islam Melalui Program Halaqah Sebagai Medium Dakwah kepada Banduan di Penjara Kajang." Jurnal Al-Hikmah (2015), 3-22.

Khairul Hamimah Mohd. Jodi. "Penerapan Nilai-nilai Islam dalam Modul Pembangunan Wanita Bermasalah di Malaysia: Kajian di Wilayah Persekutuan Kuala Lumpur." Tesis Kedoktoran, Universiti Malaya, Kuala Lumpur, 2013.

Mior Khairul Azrin Mior Jamaluddin. "Sistem Pendidikan di Malaysia: Dasar, Cabaran dan Pelaksanaan ke Arah Perpaduan Nasional." Jurnal Sosiohumanika 4, no. 1 (2011), 33-47.

Mohd Al Qayum Azizi. "Rumah Perlindungan Kanak-kanak, Wanita Wujud Sejak 1975." Laman sesawang Mstar, dicapai 5 Januari 2020, https://www.mstar.com.my/lokal/semasa/2010/10 /07/rumah-perlindungan-kanakkanak-wanita-wujud-sejak-1975. 
Noor Hafizah Mohd Haridi. "Program Agama di Institusi Pemulihan Akhlak Jabatan Kebajikan Masyarakat (JKM): Kajian dari Aspek Pelaksanaan dan Keberkesanan." Tesis Kedoktoran, Universiti Malaya, Kuala Lumpur, 2016.

Nor Jana Saim et al. "Listen to the Voices of Unwed Teenage Mothers in Malaysian Shelter Homes: An Explorative Study." Global Journal of Health Science 5, no. 5 (2013), 20-30.

Nurdeng Deuraseh dan Amaludin Ab. Rahman. "Pendekatan Keagamaan dan Kesejahteraan Rohani Teras Pencegahan HIV \& AIDS: Perspektif Responden HIV/AIDS." Jurnal Islam dan Masyarakat Kontemporari 8 (Jun 2014), 1-19.

Nurul Husna Mansor et al. "Implementasi Ibadah Islam Sebagai Terapi Salah Laku Seksual Remaja: Kajian Terhadap Pusat Perlindungan Wanita Terpilih di Selangor." International Journal of Malay World and Civilisation (IMAN) 4, no. 1 (2016), 73-84.

Nurul Husna Mansor et al. "Pemulihan Akhlak di Pusat Perlindungan Wanita: Kajian di Baitul Ehsan dan Dar Assaadah." Jurnal Hadhari 9, no. 2 (2017), 261-274.

Nurul Husna Mansor. "Modul Keagamaan untuk Remaja Hamil Luar Nikah di Pusat Perlindungan Wanita di Selangor: Kajian Pelaksanaan dan Masalah." Tesis Kedoktoran, Universiti Malaya, Kuala Lumpur, 2016.

Richard Barton. "Psychosocial Rehabilitation Services in Community Support Systems: A Review of Outcomes and Policy Recommendations." Psychiatric Services 50, no. 40 (1999), 525534.

Roslee Ahmad et al. "Strategi Intervensi Menangani Penyelewengan Tingkah Laku Seksual Berdasarkan Model AlGhazalī." Kertas kerja, Persidangan Kaunseling Kebangsaan 2009, Palace of The Golden Horses, Serdang, Selangor, 3-5 November, 2009.

Salasiah Hanin Hamjah dan Noor Shakirah Mat Akhir. "Islamic Approach in Counseling." Journal of Religion and Health (2014), 279-289.

Salasiah Hanin Hamjah et al. "The Role of the Muslim Family in Dealing with Adolescent Out-of-Wedlock Pregnancy." Mediterranean Journal of Social Sciences (December 2014), 101-106. 
Silibus Dar Assaadah-Kelas Kemahiran (Jahitan) (Kuala Lumpur: Majlis Agama Islam Wilayah Persekutuan, t.t.).

Siti Jamiaah Abdul Jalil, Yusmini Md Yusoff dan Rozmi Ismail. "Peranan Program Keagamaan Terhadap Pemulihan Konsep Kendiri Banduan Wanita di Malaysia." Jurnal al-Afkar 18, no. 2 (2016), 193-228.

Siti Marziah Zakaria dan Nur Afifah Zulkifli. "Pengalaman Remaja di Rumah Perlindungan dan Perubahan dalam Makna Hidup." Journal of Social Sciences and Humanities (2017), 1-11.

Wan Muhammad Naif Mohd Nordin dan Ahmad Dahlan Salleh. "Siasah Syar'iyyah Sebagai Mekanisma Penjagaan Akal." Jurnal Pengajian Islam, no. 10 (2017), 111-126.

Zaizul Abd Rahman et al. "Program Pemulihan Insan dalam Kalangan Banduan Melayu di Penjara Sungai Udang, Melaka." Kertas kerja, International Conference On Islamic Civilization and Malay Identity 2011 (ICICMI2011), Equatorial Hotel Melaka, Melaka, Malaysia, 14-15 November, 2011. 
Nursyahidah, Husna dan Yusmini, Bentuk-bentuk Pemulihan Akhlak 